\title{
STUDIES ON ACROSIN. I. PURIFICATION AND CHARACTERIZATION OF BOAR ACROSIN
}

\author{
SATORU KANEKO AND CHIAKI MORIWAKI
}

Laboratory of Physiological Chemistry, Faculty of Pharmaceutical Sciences, Science University of Tokyo, Ichigaya Funagawaracho, Shinjuku-ku, Tokyo, 162, Japan

(Received June 16, 1980)

Acrosin was extracted from boar sperm and purified by Sephadex gel filtration and affinity chromatography on Phe-Phe-Arg Sepharose 4B in acidic condition. Its enzymic properties were characterized in comparison with trypsin.

The oligopeptides with Arg at the carboxy-termini were used as the ligands for affinity chromatography. Phe-Phe-Arg adsorbed acrosin at $\mathrm{pH} 5$ and released it at $\mathrm{pH} 3$. To adsorb acrosin, it was found that the ligand should be longer than tripeptide with Arg in the carboxy-termini. Disc gel electrophoretogram of purified boar acrosin gave a broad band consisted from three fractions which hydrolysed $\mathrm{N}-\alpha$-benzoyl-arginine ethylester (BAEE). The $\mathrm{pH}$ optimum and inhibition spectra were similar to those of trypsin, however, the influence of urea on them were very different among each other. Calcium ion decreased $K_{\mathrm{m}}$ for BAEE, and increased $K_{\mathrm{i}}$ of aprotinin. The kinetic analysis of acrosin for its substrate and products resulted that $K_{\mathrm{m}}$ for BAEE was minimal at around $\mathrm{pH} 8$ and maximal at $\mathrm{pH} 5$, on the contrary, $K_{\mathrm{i}}$ of the product was low at $\mathrm{pH} 5$, but progressively increased along the elevation of $\mathrm{pH}$. The same tendency was observed for trypsin. From the attitudes on the affinity chromatographies and the $\mathrm{pH}$ profiles of kinetic parameters, it was concluded that the active sites of acrosin and trypsin were similar to each other.

Keywords - acrosin; trypsin; product analogue; active site; sperm

\section{INTRODUCTION}

The acrosome, an organelle located at the head of mammalian sperm, plays an important role on sperm penetration into the ovum in the fertilization. There are two acrosome enzymes which participate in the sperm penetration. One is hyaluronidase ${ }^{1)}$ which is located in acrosome vesicle and facilitates sperm penetration through the cumulus oophorus. The other is acrosin which is thought to be bound to the inner acrosomal membrane or equatrial segment and dissolves the zona pellucida. ${ }^{2,3)}$

This paper describes the purification of acrosin from the boar sperm by employing affinity chromatography, and characterization of its enzymic properties in comparison with bovine trypsin as a related enzyme.

\section{MATERIAL AND METHODS}

Boar Semen — Freshly ejaculated boar semen was obtained from Kanagawa Life Stock Improvement Association (Kanagawa, Japan).

Chemicals - N- $\alpha$-benzoyl-arginine ethylester (BAEE) was obtained from the Peptide Research Co. (Osaka, Japan). Sephadex G-150 and Sepharose 4B were from Pharmacia Fine Chem. (Uppsara, Sweden). Soybean trypsin inhibitor (SBTI), limabean trypsin inhibitor (LBTI), benzoyl-arginine (Bz-Arg), benzoyl-glycylarginine (Bz-Gly-Arg) and bovine trypsin ( $3 \mathrm{x}$ crystalized) were from Sigma Chemical Co. (St. Louis, M.O., U.S.A.). Aprotinin was obtained from Bayer A.G. (Germany). Trans aminomethyl cyclohexylic acid ( $t$-AMCHA) was provided by Eisai Co. (Tokyo, Japan). Potato kallikrein inhibitor (PKI) was purified by the method of Hojima et al. ${ }^{4,5)}$ Leucyl-arginine (LeuArg) was a gift of Prof. N. Yanaihara (Shizuoka 
College of Pharmacy). Phenylalanyl-phenylalanyl-arginine (Phe-Phe-Arg) was obtained from Nittobo Co. (Tokyo, Japan). The other chemicals used were guaranteed reagents.

Siliconized glass or plastic wares were used throughout the experiments.

Determination of Protein Concentration - Protein concentration was estimated spectrophotometrically from the absorbance at $280 \mathrm{~nm}$ (Hitachi Spectrophotometer Type 181) taking $E_{280}^{1 \%}=11.1$.

Preparation of Affinity Adsorbents - Arg, LeuArg and Phe-Phe-Arg were coupled with BrCN activated Sepharose $4 \mathrm{~B}$ according to the method of Cuatrecasas. $\left.{ }^{6}\right)$ Arg (60 mg) was dissolved in a small amount of $0.2 \mathrm{M} \mathrm{NaHCO}, \mathrm{pH} 8.1$ and coupled to $30 \mathrm{ml}$ of $\mathrm{BrCN}$ activated Sepharose 4B. Leu-Arg (100 mg) and Phe-Phe-Arg (500 $\mathrm{mg}$ ) were coupled in the same condition to $30 \mathrm{ml}$ and $100 \mathrm{ml}$ of activated Sepharose $4 \mathrm{~B}$, respectively. The coupling reaction was carried out for $2 \mathrm{hr}$ at $25^{\circ}$. The gel was treated with $0.1 \mathrm{M}$ glycine in $0.3 \mathrm{M} \mathrm{NaHCO}_{3}, \mathrm{pH} 8.1$ for several hr at $25^{\circ}$.

Disc Gel Electrophoresis - Disc gel electrophoresis was performed with $7.5 \%(\mathrm{w} / \mathrm{v})$ polyacrylamide gel at $\mathrm{pH} 4.3$. The purified acrosin was run in duplicates with $2 \mathrm{~mA} /$ tube for $3 \mathrm{hr}$. One gel was stained with Coomassie Brilliant Blue and the electrophoretogram was analysed with a Shimazu Dual Densitometer CS 901 and the other gel was sliced into $2 \mathrm{~mm}$ width by gel slicer (Hotta Rika, Tokyo) to determine enzymic activity. Each sliced gel piece was suspended in $0.3 \mathrm{ml}$ of $1 \mathrm{mM} \mathrm{HCl}$ overnight at $4^{\circ}$, acrosin activity in the extract was determined against BAEE.

Measurement of Acrosin Activity - Acrosin activity was determined by the measurement of the esterolytic activity against BAEE according to the method of Schwert and Takenaka. ${ }^{7)}$ The sample $(0.2 \mathrm{ml})$ was mixed with $2.8 \mathrm{ml}$ of $1 \mathrm{mM} \mathrm{BAEE}$ in $0.3 \mathrm{M}$ Tris- $\mathrm{HCl}$, containing $0.05 \mathrm{M} \mathrm{CaCl}_{2}, \mathrm{pH} 8.3$ at $25^{\circ}$, and the increase of absorbance at $253 \mathrm{~nm}$ was measured by Hitachi Spectrophotometer Type 124. The activity was expressed in terms of BAEE unit (BAEE U): 1 unit of activity hydrolysed $1 \mu \mathrm{mol}$ of BAEE in $1 \mathrm{~min}$.

\section{RESULTS}

\section{Purification of Acrosin}

All purification procedure was carried out at $4^{\circ}$ unless otherwise mentioned. Freshly ejaculated boar semen $(140 \mathrm{ml})$ was centrifuged $(11000 \times \boldsymbol{g}$, $20 \mathrm{~min}$ at $4^{\circ}$, and the sperm pellet was stored at $-20^{\circ}$. The frozen sperm pellet was thawed and extracted with $30 \mathrm{ml}$ of $2 \%(\mathrm{v} / \mathrm{v})$ acetic acid containing $10 \%(\mathrm{v} / \mathrm{v})$ glycerin and the supernatant was separated by centrifugation. Further extraction from the pellet was repeated twice in the same manner. The combined extracts was centrifuged $\left(105000 \times \mathrm{g}, 1 \mathrm{hr}\right.$ at $\left.4^{\circ}\right)$ and the supernatant was concentrated to $20 \mathrm{ml}$ using polyethyleneglycol 20000. Acrosin activity was not detected in this step. This was due to the contamination of considerable amount of seminal plasma acrosin inhibitor in the extract. The concentrated extract was applied to Sephadex G-150 column $(3.0 \times 90 \mathrm{~cm})$ equilibrated with $2 \%(\mathrm{v} / \mathrm{v})$ acetic acid ( $\mathrm{pH} 2.6$ ). Acrosin was separated from the inhibitor and was eluted in the fraction of 37-54 (total volume $174 \mathrm{ml}$ ) on the Sephadex G-150 column (Fig. 1). The total BAEE U in the combined active fractions was 1190.

Preliminary Experiments for Affinity Chromatography

Further purification of acrosin was carried out

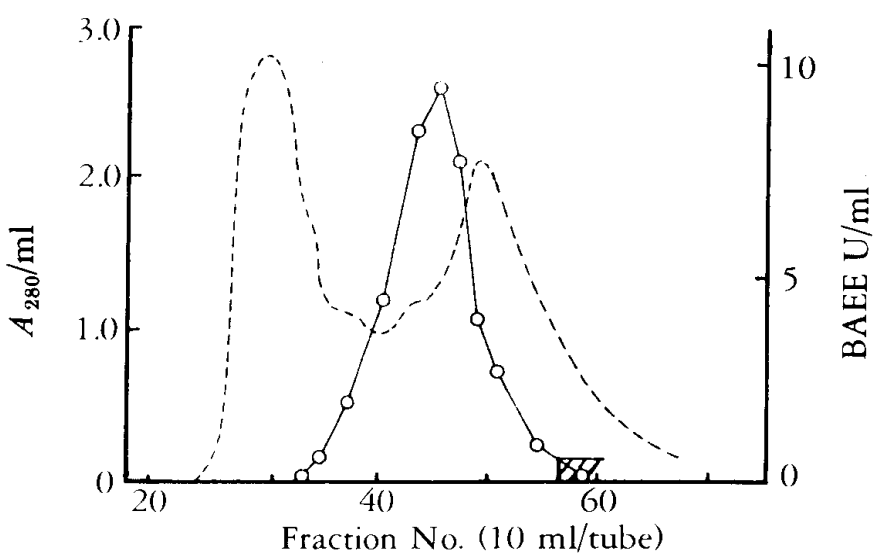

FIG. 1. Sephadex G-150 Gel Filtration of Acid Extract of Boar Sperm

Elimination of acrosin inhibitor from the active fractions (No. 37-54) was confirmed by the measurement of the activity after neutralization. $\mathbb{Z} \mathbb{Z}$ : This mark indicates the elution of the inhibitor. 
by employing affinity of the enzyme to oligopeptides with Arg at the carboxy-termini wihch have analogous amino acid sequence to the products produced by acrosin. As preliminary experiment for acrosin purification, three types of ligands, i.e., Arg, Leu-Arg and Phe-Phe-Arg were tested. Sepharose 4B coupled with each ligand was packed in a small column and equilibrated with $0.05 \mathrm{M}$ acetate buffer containing $0.5 \mathrm{M} \mathrm{NaCl}, \mathrm{pH}$ 5.3. An aliquot (20 BAEE U) of pooled fraction of acrosin from Sephadex G-150 gel filtration adjusted to $\mathrm{pH} 5.3$ by $1 \mathrm{~N} \mathrm{NaOH}$ was applied to the affinity column, and washed with the same buffer until the absorbance at $280 \mathrm{~nm}$ became negligible, then the buffer was changed to $5 \mathrm{mM}$ $\mathrm{HCl}, \mathrm{pH}$ 2.6. Acrosin was efficiently adsorbed by Phe-Phe-Arg Sepharose $4 \mathrm{~B}$ and eluted out with 5 $\mathrm{mM} \mathrm{HCl}$, but it failed to be adsorbed by Arg and Leu-Arg Sepharose 4B. According to the result of preliminary experiment, Phe-Phe-Arg Sepharose $4 \mathrm{~B}$ was used for the larger scale purification of acrosin.

Purification of Acrosin with Phe-Phe-Arg Sepharose $4 B$

The pooled active fraction from the gel filtration column was concentrated 2-fold with polyethyleneglycol 20000 and adjusted the $\mathrm{pH} 5.3$, and then applied to the affinity column $(2.0 \times 15$ $\mathrm{cm}$ ) equilibrated with $0.1 \mathrm{M}$ acetate buffer, $\mathrm{pH}$ 5.3. The column was first washed with $0.01 \mathrm{M}$ ammonium formate, $0.3 \mathrm{M} \mathrm{NaCl}, \mathrm{pH} 5.3$, then with the same solution containing $10 \%(\mathrm{v} / \mathrm{v})$ dioxane until absorbance at $280 \mathrm{~nm}$ of effluent became negligible, and finally with $5 \mathrm{mM} \mathrm{HCl}$. The acrosin activity was eluted by the final solu-

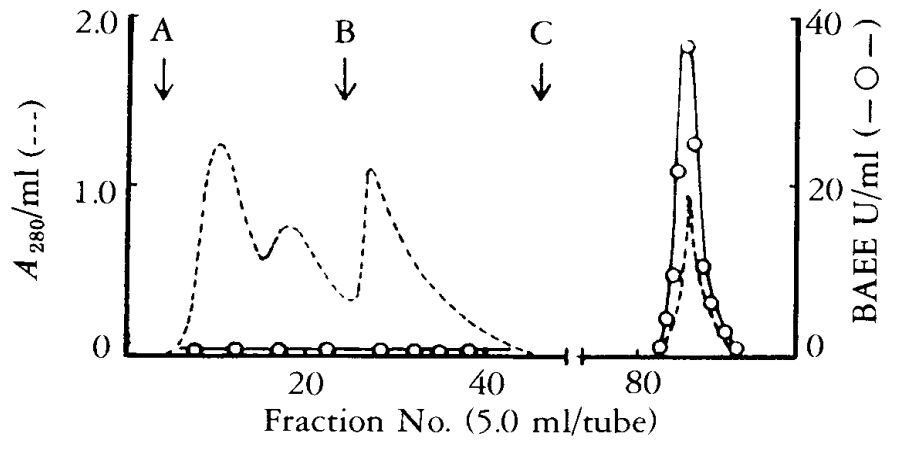

FIG. 2. Affinity Chromatography of Acrosin on PhePhe-Arg Sepharose 4B following Sephadex G-150 Gel Filtration

Arrows indicate the replacement of elution solvents.

A: $0.01 \mathrm{M} \mathrm{HCOONH}, 0.3 \mathrm{M} \mathrm{NaCl}, \mathrm{pH} 5.3$.

B: $0.01 \mathrm{M} \mathrm{HCOONH}_{4}, 0.3 \mathrm{M} \mathrm{NaCl}, 10 \%(\mathrm{v} / \mathrm{v})$ dioxane, $p H 5.3$.

$\mathrm{C}: 5 \mathrm{mM} \mathrm{HCl}$.

tion with a recovery of $96.6 \%$ (Fig. 2).

The result of purification was given in Table $\mathrm{I}$. Assuming that all the activity was recovered in the acid extract, sperm contained in $1 \mathrm{ml}$ of semen had 8.5 BAEE $U$ of acrosin activity.

Disc gel electrophoretogram of purified acrosin at $\mathrm{pH} 4.3$ gave a broad protein staining band with relatively slow mobility, but the densitometry analysis of gel indicated the broad band consisted of three peaks of protein staining (Fig. 3). The profile of BAEE activity extracted from the gel slices coincided with the density of protein staining as shown in Fig. 3.

Effects of $\mathrm{pH}$, Metal Ions, Urea and Inhibitors on the Esterolytic Activity of Acrosin

The optimum $\mathrm{pH}$ of acrosin for BAEE

\section{TABLE I. Purifivation of Boar Acrosin}

\begin{tabular}{lcccc}
\hline \hline & Total $A_{280}$ & Total BAEE U & S.A. $^{a}$ & Yield $\%^{{ }^{2}}$ \\
\hline Acid extract & 435 & - & - & - \\
Sephadex G-150 & 210 & 1190 & 5.67 & 100 \\
Phe-Phe-Arg-Sepharose 4B & 39.8 & 1149 & 28.9 & 96.6 \\
& $(35.9 \mathrm{mg})$ & & $(32.1)^{b)}$ & \\
\hline
\end{tabular}

a): Specific acitivity, $U / A_{280}$.

b): $U / m g$. 
esterolytic activity was 9.0 (Fig. 4). This was similar to that of trypsin. ${ }^{8)}$

The effects of various metal ions on the esterolytic activity of acrosin were tested (Table II). Relatively high concentrations of $\mathrm{Co}^{2+}\left(10^{-3}\right.$ M) and $\mathrm{Hg}^{2+}\left(10^{-2} \mathrm{M}\right)$ inactivated the enzyme. Potentiation of the activity was observed by the addition of $\mathrm{Ca}^{2+}$ and was found to be concentration dependent. Similar results were reported for trypsin. ${ }^{8)}$

Therefore, the influence of $\mathrm{Ca}^{2+}$ on the inhibitory effects of urea on acrosin was examined. This study was done in the presence of
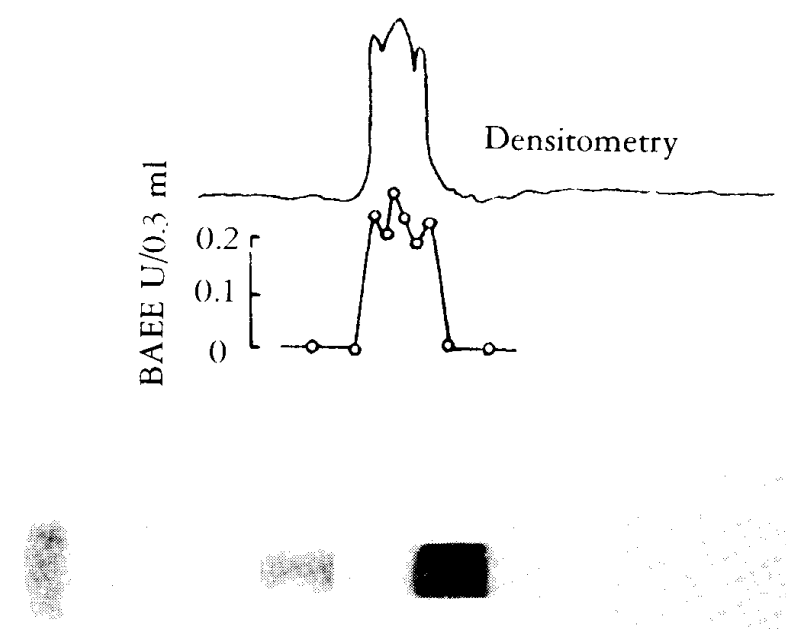

FIG. 3. Disc Gel Electrophoresis of Purified Acrosin

Gel was stained with Coomassie Brilliant Blue and densitometric tracing was carried out with dual wave length scanner at $750 \mathrm{~nm}$ (sample) and 550 $n m$ (reference).
$0.05 \mathrm{M} \mathrm{CaCl}_{2}$. The activity of acrosin decreased linearly along with the increased concentrations of urea and inactivated completely with $8 \mathrm{M}$ urea, whereas trypsin was not at all affected by $6 \mathrm{M}$ urea and $70 \%$ remained active even with $8 \mathrm{M}$ urea (Fig. 5). Thus, the effect of urea on these enzymes was different, and $\mathrm{Ca}^{2+}$ did not alter the response of them for urea (Fig. 5).

The inhibitor spectra of acrosin and trypsin were very similar. Inhibition of acrosin was observed with SBTI, LBTI, PKI and aprotinin, which were known as trypsin or kallikrein inhibitors, but not with $t$-AMCHA, a plasmin inhibitor

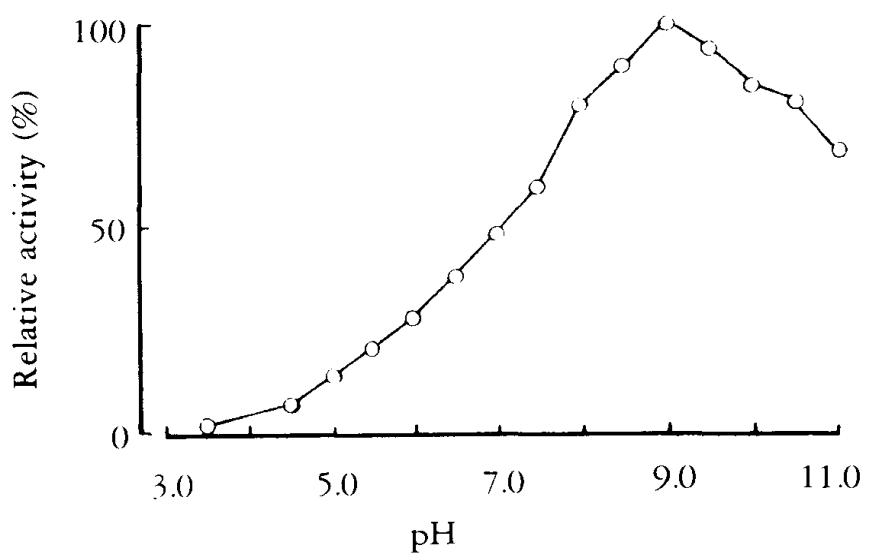

FIG. 4. Effect of $p H$ on the Esterolytic Activity of Acrosin

Substrate solution was $1.0 \mathrm{mM} \mathrm{BAEE}$ in $3.0 \mathrm{ml}$ of $0.1 \mathrm{M}$ Britton-Robinson's wide range buffer ( $\mathrm{pH}$ 3.5-11.0). Purified acrosin (0.5 U, determined at pH 8.3) was used and activity measurement was carried out as mentioned in Method. Maximum activity was expressed as $100 \%$.

TABLE II. Effects of Metal Ions on the Esterolytic Activity of Acrosin

\begin{tabular}{|c|c|c|c|c|c|c|}
\hline \multirow{2}{*}{ Metal } & \multicolumn{5}{|c|}{ Relative activity } & \multirow[b]{2}{*}{ (M) } \\
\hline & $10^{-5}$ & $10^{-4}$ & $10^{-3}$ & $10^{-2}$ & $10^{-1}$ & \\
\hline $\mathrm{HgCl}_{2}$ & 100 & 113 & 72 & 0 & - & \\
\hline $\mathrm{NiSO}_{4}$ & 98 & 98 & 104 & 109 & - & \\
\hline $\mathrm{CoCl}_{2}{ }^{4}$ & 95 & 81 & 0 & 0 & - & \\
\hline $\mathrm{CaCl}_{2}$ & 102 & 106 & 112 & 146 & 150 & \\
\hline $\mathrm{ZnCl}_{2}$ & 97 & 101 & 105 & 102 & - & \\
\hline
\end{tabular}

The substrate solution contained $1.0 \mathrm{mM} \mathrm{BAEE}$ in $0.25 \mathrm{M}$ Tris- $\mathrm{HCl}, \mathrm{pH} \mathrm{8.3,} \mathrm{containing} 10^{-5}-10^{-1} \mathrm{M}$ metal ions.

Activity of purified acrosin (0.5 U, determined in metal free substrate) was assayed without preincubation. 
(Table III). Then, the influence of $\mathrm{Ca}^{2+}$ on the inhibitory effect of aprotinin against acrosin was examined. As shown in Table III, the inhibitory activity of aprotinin was decreased in the presence of $0.05 \mathrm{M} \mathrm{CaCl}_{2}$.

In order to investigate this finding in more

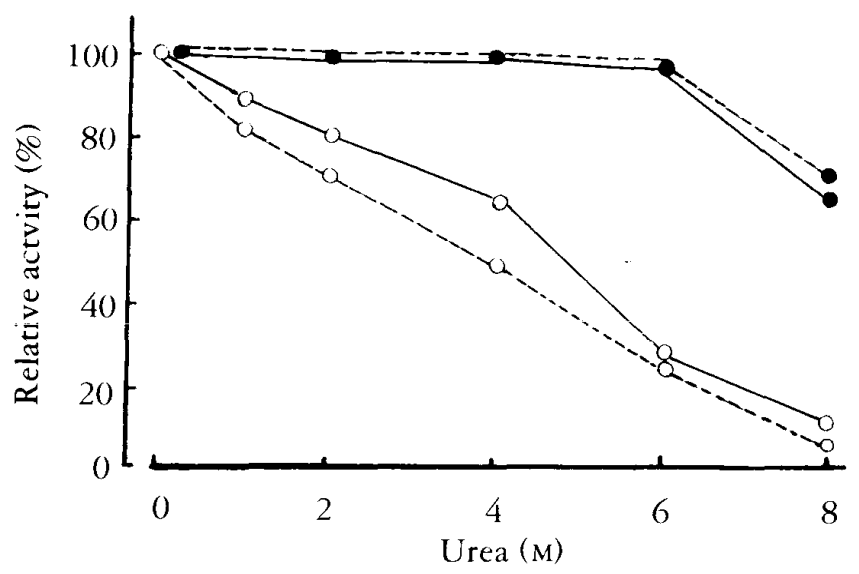

FIG. 5. Effect of Urea on the Esterolytic Activity of Acrosin

The substrate solution contained $1.0 \mathrm{mM} B A E E$, $0-8 \mathrm{M}$ urea and 0 or $0.05 \mathrm{M} \mathrm{CaCl} l_{2}$ in $0.3 \mathrm{M}$ Tris$\mathrm{HCl}, \mathrm{pH}$ 8.3. Purified acrosin and trypsin (1.0 U, determined in $0.3 \mathrm{M}$ Tris- $\mathrm{HCl}, \mathrm{pH}$ 8.3) were assayed without preincubation.

0 : Acrosin, 0 : Trypsin, Dotted and solid lines indicate the results with and without $0.05 \mathrm{CaCl}_{2}$, respectively. detail the kinetic parameters of acrosin and aprotinin were measured with and without $\mathrm{Ca}^{2+}$. Calcium ion altered the $K_{\mathrm{m}}$ value of acrosin against BAEE from 0.33 to $0.88 \mathrm{mM}$ and the $K_{\mathrm{i}}$ value of aprotinin against actosin from $5.8 \times 10^{-4}$ to $2.0 \times 10^{-2} \mathrm{mM}$. These results were in good agreement with the results shown in Table II and III.

\section{Kinetic Analysis of Acrosin Activity}

The properties of acrosin and trypsin were compared by measuring the kinetic parameters for substrate and the inhibitory effect of enzyme products at $\mathrm{pH} 5.3-8.3$. Bz-Arg and Bz-Gly-Arg, the esterolytic product of BAEE and its related compound, were the model compounds for affinity ligands. Their $K_{\mathrm{i}}$ values against acrosin at various $\mathrm{pH}$ were determined and changes of the $K_{\mathrm{i}}$ were compared with those of the $K_{\mathrm{m}}$ values of acrosin against BAEE. As shown in Fig. 6, the $K_{\mathrm{m}}$ of acrosin against BAEE was minimal at around $\mathrm{pH} 8$, indicating the affinity of the enzyme and substrate reached maximal at neutral $\mathrm{pH}$. On the contrary, the $K_{\mathrm{i}}$ values of both $\mathrm{Bz}$ Arg and Bz-Gly-Arg were low at acidic $\mathrm{pH}$ (around $\mathrm{pH}$ 5) but progressively increased at neutral $\mathrm{pH}$. The enzyme had higher affinity with those compounds at acidic $\mathrm{pH}$ and lesser affinity

TABLE III. Effects of the Inhibitors on the Esterolytic Activity of Acrosin

\begin{tabular}{lccccc}
\hline \hline & \multicolumn{5}{c}{ Inhibition $(\%)$} \\
\cline { 2 - 6 } (a) & 1 & 10 & $10^{2}$ & $10^{3}$ & $\mu$ g inhibitor \\
\hline LBTI & 70.6 & 87.3 & 86.3 & 86.9 & \\
SBTI & & 1.9 & 82.9 & 87.3 & \\
PKI & & 1.8 & 15.2 & 87.2 & \\
t-AMCHA & & 0 & 0 & 0 & \\
\hline \hline \multicolumn{1}{c}{ (b) } & $\mathrm{CaCl}_{2}(\mathrm{M})$ & 10 & $10^{2}$ & $10^{3}$ & $\mathrm{KIU}$ \\
\hline \multirow{2}{*}{ Aprotinin } & 0 & 50.2 & 76.8 & 85.9 & \\
& 0.05 & 0 & 13.7 & 64.4 & \\
\hline
\end{tabular}

KIU: Kallikrein inhibitor unit.

(a) Equal volume of purified acrosin $(1.0 \mathrm{U} / \mathrm{ml}, 0.3 \mathrm{M}$ Tris- $\mathrm{HCl}, \mathrm{pH} \mathrm{8.3)}$ and the inhibitors $20-2000$ $\mu \mathrm{g} / \mathrm{ml}$ ) were mixed and incubated for $10 \mathrm{~min}$ at $25^{\circ}$. The remaining activity was measured and the results were expressed by \% inhibition.

(b) Acrosin and aprotinin $(20-2000 \mathrm{KIU})$ were treated as above with or without $\mathrm{Ca}^{2+}$. 

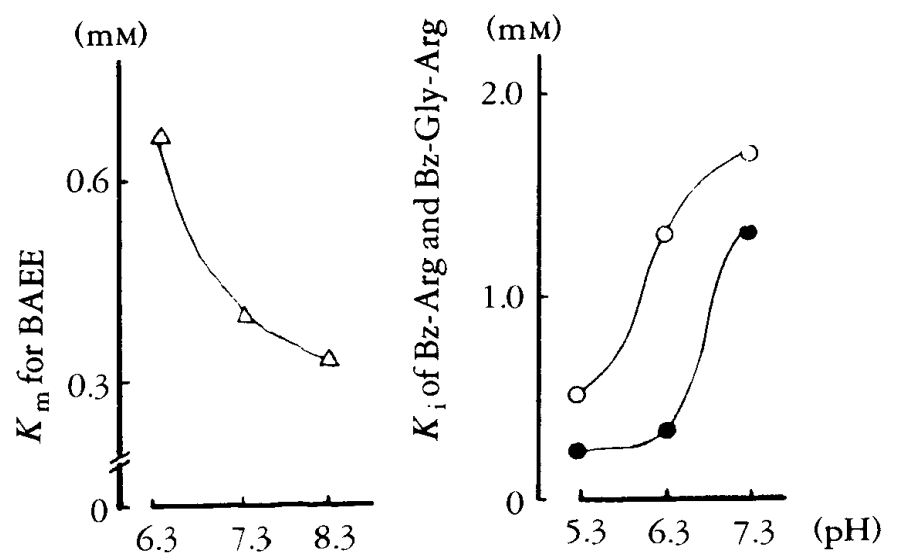

FIG. 6. Kinetic Parameters of Acrosin for Substrate and Products at Various pH's

One unit of acrosin (with $1.0 \mathrm{mM} B A E E$ in $0.2 \mathrm{M}$ Tris- $\mathrm{HCl}, \mathrm{pH} 8.3,25^{\circ}$ ) was used for kinetic studies. Tris- $\mathrm{HCl}$ buffer $(0.2 \mathrm{M})$ was used for $\mathrm{pH}$ 's 8.3 and 7.3, and acetate buffer $(0.2 \mathrm{M})$ was for pH's 6.3 and 5.3.

(a) The $K_{m}$ values of acrosin at various $p H$ 's were obtained by the Lineweaver-Burk plots using 0.083-0.25 mM BAEE.

(b) The $K_{i}$ values of $B z-A r g(\bigcirc)$ and Bz-GlyArg (@) were obtained by using the concentration of $0.2 \mathrm{mM}$ and $0.1 \mathrm{mM}$ of the respective compounds. The range of $B A E E$ concentration was the same as (a) and $K_{i}$ values were calculated by the Lineweaver-Burk plots.

at neutral environments. This result supports the fact that acrosin was adsorbed by Phe-Phe-Arg Sepharose 4B which had a product analogue type ligand at relatively low $\mathrm{pH}$. The $K_{\mathrm{i}}$ values of $\mathrm{Bz}$ Gly-Arg at various $\mathrm{pH}$ were always lower than those of $\mathrm{Bz}-\mathrm{Arg}$, this result indicates that insertion of Gly into the $\mathrm{Bz}$-Arg bond induces an increase of affinity. The same tendency was also observed for trypsin..$^{9)}$

\section{DISCUSSION}

Proteolytic activity in acrosome was first described by Stambaugh and Buckley (1968) in rabbit sperm, ${ }^{2}$ and this enzyme was named acrosin by Zaneveld et al. (1972). ${ }^{3)}$ Schleuning et al. (1973) purified boar acrosin by affinity chromatography on $p$-aminobenzamidine (an inhibitor of acrosin)cellulose. ${ }^{10)}$ Acrosin was adsorbed on this ligand at $\mathrm{pH} 7-8$ and eluted at $\mathrm{pH} 3$. We employed product analogue ligand, Phe-Phe-Arg coupled to Sepharose $4 \mathrm{~B}$, for acrosin purification; this ligand adsorbed acrosin at $\mathrm{pH} 5$ and released it at $\mathrm{pH} 3$.

Kasai et al. have described affinity chromatography of trypsin on the product analogue ligands which were oligopeptides with Arg at carboxytermini. ${ }^{11)}$ Their experiment was useful to discuss about the active site of trypsin. They found that the $\mathrm{pH}$ dependency of the affinity for its substrate and products were reversed. ${ }^{12)}$ Trypsin bound to the product analogue ligands at $\mathrm{pH} 5$ and dissociated at $\mathrm{pH} 3 .{ }^{11)}$ The ligands required were no shorter than tripeptides to absorb trypsin. ${ }^{11}$ ) Ligand elongation increased the affinity of trypsin due to the lesser steric hindrance by Sepharose beads. ${ }^{6,13)}$ This relates to the depth of substrate binding pocket of trypsin molecule; they suggested that the depth of binding pocket of trypsin seemed to correspond roughly with the length of tripeptides." Acrosin hydrolysed BAEE and this activity was inhibited by SBTI, hence acrosin is recognized as one of trypsin-like enzyme. In this investigation, the product analogue ligands of different length were employed for study of the nature of its active site. Both acrosin and trypsin were adsorbed by tripeptides-Sepharose (PhePhe-Arg Sepharose 4B), which indicates that the depth of binding pockets of acrosin and trypsin are similar to each other. Thus, we could demonstrate the similarity of the active sites of acrosin and trypsin by use of the product analogue ligand in affinity chromatography.

The disc gel electrophoretogram of purified acrosin showed a broad band consisted of three protein peaks, all of which showed acrosin activity. Schleuning et al. also found similar observation in their acrosin preparation, and they suggested that these multiple forms were produced by autolysis corresponding to $\alpha, \beta$ and $\gamma$ forms of trypsin. ${ }^{14)}$ They incubated $\alpha$ and $\beta$ forms of acrosin preparation at $\mathrm{pH} 8.0$ and observed their conversion to the $\gamma$ form. This conversion was prevented by addition of acrosin inhibitor, such as $p$-nitrophenyl-guanidinobenzoate. ${ }^{15)}$ Schleuning et al. performed affinity chromatography at $\mathrm{pH}$ 
$8,{ }^{10)}$ so it might have been possible to have generated multiple forms by autolysis during purification. However, as we carried out all the purification procedures below $\mathrm{pH} 5.3$ at $4^{\circ}$, it is unlikely that the formation of multiple forms occurred in the purification procedures. Those multiple forms might have been produced in the activation process of proacrosin, although the mechanism still remains to be answered.

Stambaugh and Smith reported that the amino acid composition of rabbit acrosin was similar to that of bovine and human pancreatic trypsin, but acrosin lacked half cystine. ${ }^{16)}$ The different effects of urea on acrosin and trypsin (Fig. 5) suggests that the denaturation may be related to the rigidity of the enzyme molecule by disulfide bonds.

The results obtained in this investigation supported that the enzymic properties of acrosin and trypsin were very similar. The fact that alteration of $K_{\mathrm{m}}$ and $K_{\mathrm{i}}$ values of acrosin according to the change of $\mathrm{pH}$ (Fig. 6) is similar to those of trypsin suggests that these enzymes have a very similar type of active site. Such $\mathrm{pH}$ dependencies of kinetic parameters are characteristic for trypsin and its related serine enzymes.

In the fertilization processes, capacitation and acrosome reaction take place and $\mathrm{Ca}^{2+}$ have been proven to be essential for the latter. Yanagimachi et al. ${ }^{17,18)}$ reported that guinea pig sperm could be capacitated in $\mathrm{Ca}^{2+}$ free medium, whereas acrosome reaction failed to occur in this medium. The addition of $\mathrm{Ca}^{2+}$ to the medium, however, induced the reaction. For the sperm penetration through the ovum membranes, two enzymes, hyaluronidase and acrosin, are known to be required. Hyaluronidase, however, is insensitive to $\mathrm{Ca}^{2+}{ }^{1)}$ In this report we have investigated the possible function of $\mathrm{Ca}^{2+}$ to acrosin activity with the relationship to its inhibitor. Calcium ion decreased $K_{\mathrm{m}}$ value of acrosin and increased $K_{\mathrm{i}}$ value of aprotinin against acrosin. Our results agreed the finding of Brown et al. ${ }^{19)}$ that $\mathrm{Ca}^{2+}$ suppressed the inhibitory activity of Kunitz pancreatic trypsin inhibitor on acrosin but not on trypsin. Acrosin inhibitor is located on the surface of the ejaculated sperm and the release of the inhibitor from the sperm might be a part of capacitation process. ${ }^{20,21)}$ The fact that $\mathrm{Ca}^{2+}$ increased the $K_{\mathrm{i}}$ value of aprotinin against acrosin suggests that the role of $\mathrm{Ca}^{2+}$ in the fertilization processes may be not only to initiate the acrosome reaction but also to regulate the acrosin activity along with the endogeneous acrosin inhibitor.

Acknowledgment The authors wish to express their thanks to Prof. N. Yanaihara for donation of Leu-Arg. Thanks are also given to Kanagawa Life Stock Improvement Association for supply of boar semen.

\section{REFERENCES}

1) L.J.D.Zaneveld, K.L.Polakoski and G.F.B.Schumacher: Properties of acrosomal hyaluronidase from bull spermatozoa, J. Biol. Chem ., 248, 564-570 (1973).

2) R.Stambaugh and J.Buckley: Zona pellucida dissociation enzymes of rabbit sperm head, Science, 161, 585-590 (1968).

3) L.J.D.Zaneveld, B.M.Dragoje and G.F.B.Schumacher: Acrosomal proteinase and proteinase inhibitors of human spermatozoa, Science, 177, 702-705 (1972).

4) Y.Hojima, H.Moriya and C.Moriwaki: Studies on kallikrein inhibitors in Potatoes. I, Partial purification and some properties, J. Biochem., 69, 1019-1025 (1971).

5) Y.Hojima, H.Moriya and C.Moriwaki: Studies on kallikrein inhibitors in potatoes. II. Effect of potato kallikrein inhibitors on various kallikreins and other proteinases, J. Biochem ., 69, 1027-1032 (1971).

6) P.Cuatrecasas: Protein purification by affinity chromatography, J. Biol. Chem ., 245, 3059-3065 (1970).

7) G.W.Schwert and Y.Takenaka: A spectrophotometric determination of trypsin and chymotrypsin, Biochim. Biophys. Acta, 16, 570-575 (1955).

8) D.H.Dixon, D.L.Kaufman and H.Neurath: Amino acid sequence in the region of diisopropyl phosphoryl binding site in diisopropyl phosphoryl-trypsin, $J$. Biol . Chem ., 233, 1373-1381 (1958).

9) K.Kasai and S.Ishii: Quantitative analysis of affinity chromatography of trypsin, J. Biochem ., 77, 261-264 (1975).

10) W.D.Schleuning, H.Schiessler and H.Fritz: Highly purified acrosomal proteinase (Boar acrosin); Isolation by affinity chromatography using benzamidine cellulose and stabilization, Hoppe-Seyler's Z. Physiol. Chem ., 354, 550-554 (1973).

11) K.Kasai and S.Ishii: Affinity chromatography of trypsin using a Sepharose derivative coupled with peptides 
containing L-arginine in carboxy termini, J . Biochem , 71, 363-366 (1972).

12) K.Kasai and S.Ishii: Affinity chromatography of trypsin and related enzymes, J. Biochem ., 78, 653-662 (1975).

13) P.Cuatrecasas: The puprification of $\beta$-galactosidase from E. Coli. by affinity chromatography, J. Biol. Chem ., 246, 196-200 (1971).

14) W.D.Schleuning, R.Hell and H.Fritz: Multiple forms of human acrosin; Isolation and properties, HoppeSeyler's Z. Physiol. Chem ., 357, 855-865 (1976).

15) G.S.Borhan, W.D.Schleuning, H.T.Tschesche and H.Fritz: Occurrence of multiple forms of bull and ram acrosin during proenzyme activation and inhibition of activation by $p$-nitrophenyl-guanidinobenzoate, Hoppe-Seyler's Z. Physiol. Chem., 357, 667-671 (1976).

16) R.Stambaugh and M.Smith: Amino acid content of rabbit acrosomal proteinase and its similarity of pancreatic trypsin, Science, 186, 745-751 (1974).
17) R.Yanagimachi and C.A.Mahe: In vitro capacitation of golden hamster spermatozoa by homologous and heterologous blood sera, Biol. Reprod., 3, 147-153 (1970).

18) R.Yanagimachi and C.A.Mahe: The sperm acrosome reaction and fertilization in the guinea pig, a study in vitro, J. Reprod. Fertil ., 46, 49-54 (1976).

19) C.R.Brown and E.F.Hartree: Effects of acrosin inhibitors on the soluble and membrane bound forms of ram acrosin, and a reappraisal of the role of the enzyme in fertilization, Hoppe-Seyler's Z. Physiol. Chem., 357, $57-65$ (1976).

20) L.J.D.Zaneveld, P.N.Srivastava and W.L.Williams: Relationship of a trypsin like enzyme in rabbit spermatozoa capacitation, J. Reprod . Fertil ., 20,337-339 (1969).

21) L.J.D.Zaneveld, R.T.Robertson, M.Kessler and W.L.Williams: Inhibition of fertilization in vivo by pancreatic and seminal plasma trypsin inhibitors, $J$. Reprod. Fertil ., 25, 387-391 (1971). 